\title{
Anatomia do lenho de 4 espécies de Zanthoxylum Linnaeus (Rutaceae) da Amazônia
}

\author{
Arthur A. Loureiro ( $\left.{ }^{*}\right)$ \\ Francisco José de Vasconcelos (*) \\ Byron W. P. de Albuquerque (")
}

\begin{abstract}
Resumo
No presente trabalho, os autores apresentam o estudo dos caracteres anatômicos das madeiras de 4 espécies do gênero Zanthoxylum (Rutaceae) e, para cada uma delas, são apresentadas informações sobre: a) a árvore: descrição botânica, dispersão geográfica, habitat, fenologia e nomes vulgares; b) a madeira: caractersticas gerais, descrição microscópica, usos comuns, 8 microfotografias do lenho das espécies estudadas, 4 pranchas esquemáticas contendo as diversas formas dos elementos vasculares e um quadro apresentando as principais caractersticas e diferenças anatômicas das espécies. As espécies estudadas foram: Zanthoxylum compactum (Huber ex Albuquerque) Albuquerque, $\mathbf{Z}$. dellomei (de Albuquerque) Waterman, $\mathbf{Z}$. machadoi (de Albuquerque) Albuquerque e $Z$. rhoifolium Lamarck.
\end{abstract}

\section{INTRODUÇÃO}

De um modo geral, as madeiras das Rutáceas amazônicas têm sido pouco estudadas anatomicamente e pouco usadas pelo homem no mercado madeireiro, principalmente a maioria das espécies do gênero Zanthoxylum ( $\mathrm{Fa}$ gara). Neste gênero, que reune mais de 50 espécies distribuídas desde a América do Norte até o sul da América do Sul, foram feitos estudos anatômicos das madeiras de apenas 6 espécies (Milanez, 1943; Record \& Hess, 1949; Albuquerque \& Honda, 1972; Loureiro \& Lisbôa, 1979) .

Segundo Record \& Hess (1940 e 1949), a única madeira comercial conhecida é o "Paucetim", representado notadamente pela espécie Zanthoxylum flavum Vahl, cuja distribuição está assinalada para República Dominicana, Porto Rico, Ilhas Bahamas, Bermudas e o Sul da Fióricia, sendo todavia também registrada na Guiana Francesa. Sua madeira é pesada, dura, de textura fina com grã ondulada de bo- nito aspecto, de cor amarela creme ou dourada, com aparência e tato oleosos, e quando recen. temente trabalhada fornece um odor pronunciado de coco. Conhecida no mercado de móveis finos durante muito tempo é empregada em todas as obras de gabinete, interiores e embutidos.

$\mathrm{Na}$ Amazônia, o emprego das madeiras do gênero Zanthoxylum até agora conhecidas, é o mais variado (Correa, 1931; Le Cointe, 1974; Cowan \& Smith, 1973; Loureiro \& Lisboa, 1979). Algumas de suas espécies são utilizadas para tamancos, cabos de ferramentas e instrumentos agrícolas, remos, carroçaria, marcenaria, construção civil, ripas, saltos de sapato, etc. merecendo destaque $Z$. rhoifolium Lam. por apresentar durabilidade média, resistente, leve, de superfície lisa e lustrosa, recebendo bom acabamento .

\section{MÉTodos E MATERIAL}

MÉTODOS

Para a descrição microscópica do lenho, utilizcu-se a norma técnica adotada pela Associação Brasileira de Normas Técnicas (1973), para as descrições dos caracteres microscópi$\cos$ das madeiras de dicotiledôneas brasileiras.

Das amostras registradas na Xiloteca do Instituto Nacional de Pesquisas da Amazônia - INPA, foi retirado um corpo de prova com as dimensões de $1,5 \mathrm{~cm}$ na direção tangencial, $2,0 \mathrm{~cm}$ de direção radial e $3,0 \mathrm{~cm}$ na direçáo axial. Os corpos de prova foram fervidos em água pelo período aproximado de 1 (uma) hora, impregnando, sempre que necessário, com parafina a fim de evitar a dilaceração ou rompimento dos elementos constituintes do

$\left({ }^{\bullet}\right)$ - Instituto Nacional de Pesquisas da Amazônia, Manaus: 
lenho. Em seguida, foram feitos os cortes transversais ao eixo da árvore, e os outros no sentido longitudinal: perpendicularmente aos raios (tangenciai) e paralelamente a estes (radial), variando a espessura dos cortes entre 16-18 $\mu \mathrm{m}$, no micrótomo Jung. R. Jungag, dividindo o corte em três tipos: uns em cor natural, outros coloridos pela safranina hidroalcoólica e alguns em verde iodo, que foram montados em bálsamo do canadá entre lâmina e lamínula.

Para a maceração, foram utilizadas pequenas lascas de madeira da parte mais interna do corpo de prcva, que foram colocadas em contato com a solução aquosa de ácido nítrico a $40 \%$. Para acelerar a reação do $\mathrm{HNO}_{3}$, colocou-se o macerado na estufa a $50-60^{\circ} \mathrm{C}$ por 2 dias. Decorridos os dois dias, o material foi lavado em água corrente e corado com safranina hidroaicoólica. Feita a coloração, realizouse nova lavagem, dissociando-se sobre lâmina em uma gota de glicerina, com auxílio de aguIhas histológicas e microscópio estereoscópio Olympus. Logo em seguida, procedeu-se à montagem e lutagem das lâminas para, em sequida, serem feitas as devidas mensurações.

$\mathrm{Na}$ mensuração das fibras, número de vasos por milímetros quadrado, diâmetro tangencial dos poros, número de raios por milímetro linear, altura dos raios em $\mu \mathrm{m}$ e comprimento dos elementos vasculares, utilizou-se o Projetor Universal UP-360-T II Olympus com a objetiva de $100 \mathrm{X}$ e escala de vidro com $0,5 \mathrm{~mm}$ de unidade mínima de graduação equivalente a $10 \mu \mathrm{m}$ com respectiva objetiva.

\section{MATERIAL}

O material estudado encontra-se registrado e catalogado no Herbário e Xiloteca do INPA.

\section{Resultados}

Os resultados apresentados obedecem a uma seqüência alfabática dos nomes das espécies.

As microfotografias com $50 \mathrm{X}$ de aumento foram obtidas diretamente das lâminas histológicas com microscópio Olympus Trinocular FH, câmara Olympus.
As fotos sai dispostas seguindo a ordem alfabética das espécies estudadas.

1. Zanthoxylum compactum (Huber ex Albuquerque). Albuquerque, Acta Amazonica $6(3): 50$, foto 32. 1976 (Suplemento) .

Fagara compactum Huber ex Albuquerque, Publ. INPA 27: 12, tab. II; idem, Bol. INPA, Pesq. Flor. 13: 18-19, fig. 7, T. 1970.

\section{a) DADOS GERAIS SOBRE A PLANTA}

Árvore pequena a mediana até cerca de $18 \mathrm{~m}$ de altura e $35 \mathrm{~cm}$ de diâmetro de fuste (D.A.P.), com ramos cobertos de manchas esbranquiçadas. Folhas paripinadas, raramente imparipinadas, de 2-7 pares de folíolos oblongoelíticos, coriáceos, glabros, brilhantes em ambos os lados, translúcido-pontuados, base aguda e ápice obtuso-acuminado, margem indistintamente ou levemente crenulada, glandulífera. Inflorescência em panículas terminais, amplas. Flores masculinas esbranquiçadas, pequenas, com pedicelos curtos; cálice cupular, 5-laciniado, lacínios livres, ovado-triangulares; corola de 5 pétalas oblongo-elíticas; estames 5 , filetes achatados na base e atenuados para o ápice. anteras ruivas, ovado-oblongas; ovário rudimentar com 5 lóculos separados, com estígmas dispostos sobre um ginóforo glabro. Flores femininas desconhecidas. Fruto 4-5 cocas, vermelho-escuras quando maduras, cochiformes, subglobosas, carinadas, concrescidas na base, deiscentes em duas valvas arqueadamente sulcadas, rugoso-glandulosas, dispostas em ramos frutíferos curtos, compactos; semente 1, rugosa.

Dispersão geográfica: No Brasil, assinalada para o Estado do Pará, Município de Faro, Paraná do Adauacá; Município de Oriximiná, Lago Salgado, no rio Cuminá, afluente do baixo rio Trombetas; Município de Óbidos, Óbidos (cidade); e Estado do Amazonas, Município de Parintins, Porto Santa Julia, próximo a Parintins (cidade): Municipio de Manaus, lagos do Janauari e do Aleixo. Colômbia: Departamento Amazonas, rio Loreto-Yaco.

Habitat: Em mata primária de várzea. 


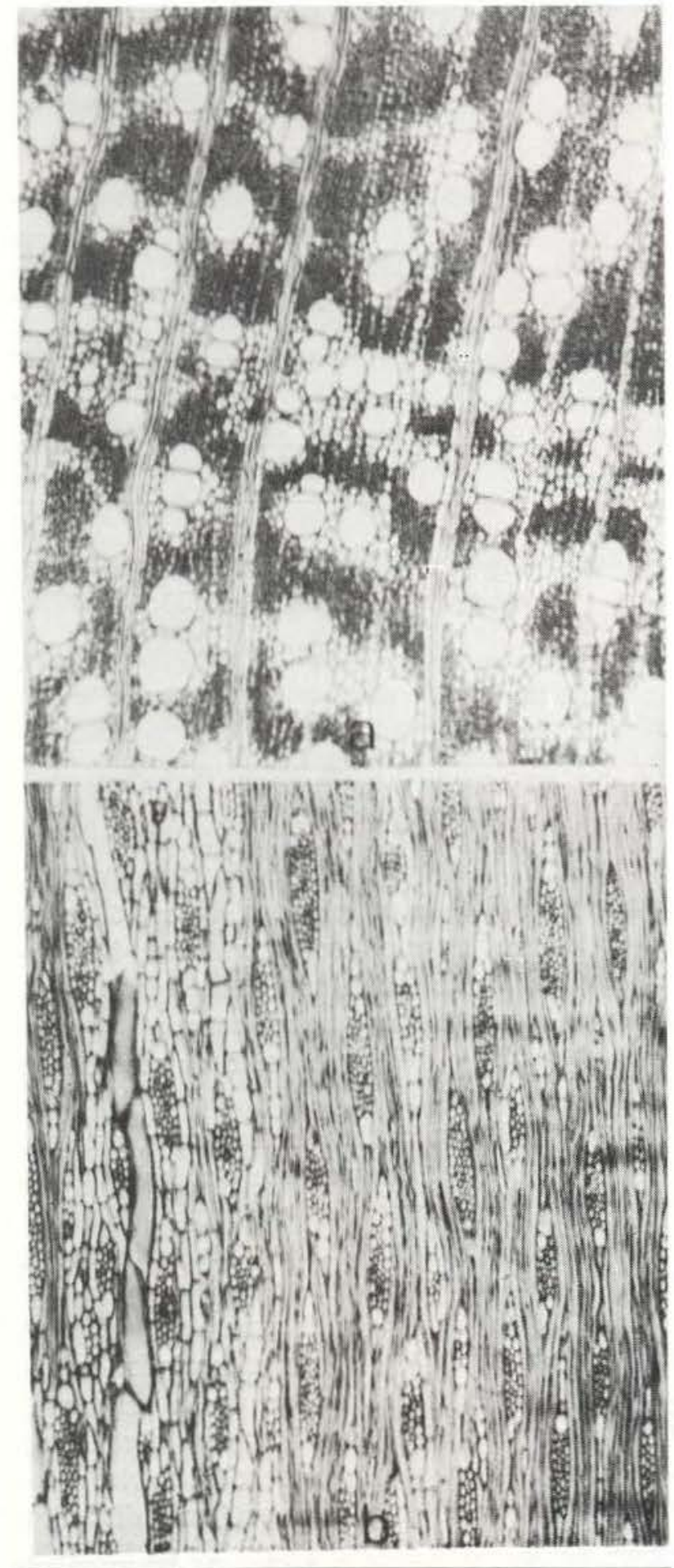

Foto I - Zanthoxylum compactum: a) - secção transversal (50X); b) - secção tangencial (50X).

Fenologia: Floração assinalada para os meses de maio, junho, agosto e dezembro e a frutificação para os meses de janeiro e maio. Nomes Vulgares: Tamanqueira (Pará) e Limão. rana (Amazonas).

\section{b) DADOS GERAIS SOBRE A MADEIRA}

\section{Características gerais da madeira}

Madeira moderadamente pesada $(0,70$ a $0,75 \mathrm{~g} / \mathrm{cm}^{3}$ ), cerne creme, alburno amarelado; cheiro não pronunciado; gosto indistinto; textura final : grã direita para irregular, mas um tanto difícil de ser trabalhada com ferramentas mecânicas em virtude de conter grande quantidade de cristais. Brilho pouco pronunciado, recebendo bom acabamento com polimento.

\section{Descrição microscópica}

Vasos de distribuição difusa, de secção oval a circular, parede de 3-6 $\mu \mathrm{m}$ de espessura; extremamente pequenos a pequenos, variando de 30-100 $\mu \mathrm{m}$ de diâmetro tangencial, predominam os pequenos de 70-100 $\mu \mathrm{m}$ com $72 \%$; em sua maioria vazios, rarissimos ou parcialmente obstruídos por tilos; muito numerosos a numerosíssimos de 25-54 por $\mathrm{mm}^{2}$, predominância dos solitários com $54 \%$, múltiplos de $2 \mathrm{com} 35 \%$, múltiplos de $3-4 \mathrm{com} 11 \%$, alguns aglomerados em cachos e notam-se anéis porosos associados ao parênquima; placa de perfuração simples, inclinada e retas; pontuações intervasculares areoladas, disposição alterna, medindo $3 \mu \mathrm{m}$; forma poligonal para irregular; disposição da abertura da pontuação horizontal, inclusa; comprimento dos elementos vasculares de muito curtos a longos, com uma variação de 230-560 $\mu \mathrm{m}$, maior predominância de curtos a longos, na faixa de $331-530 \mu \mathrm{m}$ com $76 \%$; alguns com apêndices curtos, outros longos, de um só lado ou ambos os lados e sem a presença de apêndices conforme mos. tra o desenho esquemático da Fig. 1. Raios de disposição irregular, heterocelulares, predominam os pentasseriados com $42 \%$, tetrasseriados com $28 \%$, hexasseriados com $18 \%$, trisseriados com $8 \%$, bi e unisseriados com $4 \%$; 6-9 raios por m.m, com maior freqüência de 8-9 com 52\%; 6-12 células de altura, com maior predominância de $11-15$ células $(48 \%)$, raros de 2 e 27 células, e ainda fusionados de 15 e 23 células: extremamente baixos a muito baixos, variando de $110-680 \mu \mathrm{m}$ de altura, pre- 

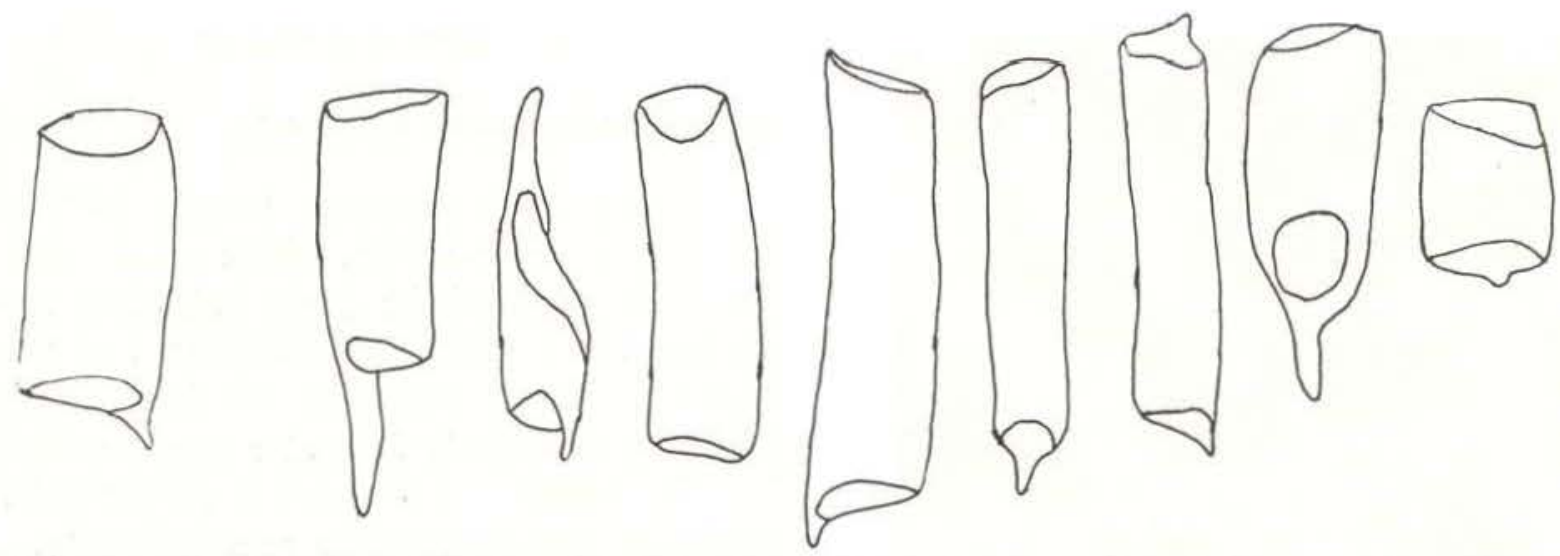

$0,2 \mathrm{~mm}$

Fig. $1-$ Zanthoxylum compactum

dominando os extremamente baixos com 210-310 $\mu \mathrm{m}$ (40\%), alguns fusionados de 500 e $68 \mathrm{um}$, raríssimos os raios que se fusionam até 3 : pontuações radiovasculares do mesmo tipo cias intervasculares. Parênquima axial abunciante em relação às demais espécies, paratraqueal, formando pequenas faixas obliquamente ligando e envolvendo irregularmente dois ou mais vasos; difuso, constituído de células esparsas, delimitando também as camadas de crescimento em associação com os vasos, notando-se a presença do abaxial e ainda vasicêntrico incompleto. Cristais muito abundantes, prismáticos de diversas formas, com possibilidades de: ser oxalato de cálcio; no corte transversal aparecem em abundância nas células do parênquima axial e radial; no corte tangericial são vistos em abundância no ápice dos raios e no parênquima seriado; no corte radial em abundância, dispersos nos raios e parênquima axial. Mácuias medulares não foram observadas. Fibras libriformes, parede de $3 \mu \mathrm{m}$ de espessura, diâmetro do lúmen variando de 3 a $6 \mu \mathrm{m}$; curtas, de 1160-1500 $\mu \mathrm{m}$ de comprimento, mais comumente de 1160-1360 $\mu \mathrm{m}$ $(80 \%)$. Camadas de crescimento demarcadas aparentemente pela associação dos vasos e parênquima e pelo diâmetro diminuto dos vasos.

Empregos: Taboas, vigas portas, ripas, saltos de sapato, marcenaria, etc.

Material examinado: $X-3995$ (Herb. 23922), B. W. de Albuquerque \& L. Coelho, 68-123.
2. Zanthoxylum dellomei (de Albuquerque) Waterman, Taxon $24(2 / 3)$ : 363.1975.

Fagara dellomei Albuquerque, Publ. INPA 27: 3, tab. 1. 1968; idem, Bol. INPA, Pesq. Flor, 13: 14-15, fig. 7, N. 1970.

\section{a) DADOS GERAIS SOBRE A PLANTA}

Árvore até $24 \mathrm{~m}$ de altura; ramos purpúreos, suberosos. Folhas paripinadas, com 3-5 pares de folíolos oblongo-elíticos, coriáceos, brilhantes em ambas as faces, translúcido-pontuados, de base aguda $s$ ápice agudo-acuminado, margem crenulada a partir de baixo da metade da lâmina foliolar para o ápice, e glandulífera. Inflorescência em panículas terminais, amplas, de poucas flores. densamente pubérulas. Flores masculinas amarelas, pequenas, sésseis; cálice de 5 sépalas subobovadas, imbricadas, munidas de glândulas, com margem curtamente ciliada; corola de 5 pétalas amarelas, oblongoelíticas; estames 5 , glabros, alternipétalos, filetes atenuados, achatados, de base larga, anteras esbranquiçadas, oblongas, dorsifixas, de base profundamente bilobada; ovário rudimentar trilocular, liso sem estígma, disposto sobre um ginóforo glabro e provido na base de 5 apófises alternas aos estames e estilete rudimentar. Flores femininas e frutos desconhecidos.

Dispersão geográfica: Brasil, assinalada para o Estado do ..Pará, Município de Almeirim, região do rio Tiriós, afluente do alto rio Paru ou Paru de Este.

Habitat: Em mata primária de terra firme. 
Fenologia: Colhida com flores masculinas no mês de março.

Nomes Vulgares: Desconhecidos.

\section{b) DADOS GERAIS SOBRE A MADEIRA}

\section{Caracteristicas gerais da madeira}

Madeira pesada $\left(0,90 \mathrm{~g} / \mathrm{cm}^{3}\right)$; alburno creme, cerne creme-escuro; gosto adstringente, cheiro indistinto; grã direita; textura média; superficie brilhosa. Boa de ser trabalhada, recebendo um acabamento esmerado.

\section{Descrição microscópica}

Vasos de forma circular a ovalada, distribuição difusa, parede de $3.9 \mu \mathrm{m}$ de espessura; pequenos a médios, de diâmetro tangencial entre 90-200 $\mu \mathrm{m}$, raros os de 60 e 70 $\mu \mathrm{m}$, predominando os médios, maioria de $110-140 \mu \mathrm{m}(76 \%)$ vazios; poucos numerosos, de 6-10 por $\mathrm{mm}^{2}$, predominância de $8-9$, esporadicamente até 11 por $\mathrm{mm}$; predominando os múltiplos de $2(47 \%)$, solitários $(39 \%)$, de $3-4(14 \%)$; placa de perfuração simples algumas retas, outras inclinadas; pontuaçōes intervasculares em disposição alterna, medindo 6 $\mu \mathrm{m}$; forma circular, poligonal e irregular; disposição da abertura da pontuação horizontal, inclusa; elementos vasculares de curtos a longos, variando de $310-700 \mu \mathrm{m}$, maior freqüência de $401-700 \mu \mathrm{m}(88 \%)$, ocasionalmente muito longos; apresentam apêndice em uma extremidade, sm ambas extremidades e sem presença de apêndices, conforme desenho esquemático da Fị̣. 2. Raios heterogêneos, de distribuição irregular; de 230-1000 $\mu \mathrm{m}$ de altura, extremamente baixos a muito baixos, maior predominância entre 410-1000 $\mu \mathrm{m}$ (88\%); tetrasseriados predominantes $(62 \%)$, trisseriados $(26 \%)$. bisseriados e unisseriados (12\%); de 7-47 células de altura, maioria entre 18-28 células $(56 \%)$, apresentando apenas um raio fusionado com 38 células de altura; alguns com tendência a fusionar-se; de 3-6 raios por $\mathrm{mm}$, com maior freqüência entre $3-4(60 \%)$; pontuações radiovasculares do mesmo tipo das intervasculares. Parênquima axial paratraqueal em linhas concêntricas, afastadas entre si e, às vezes,

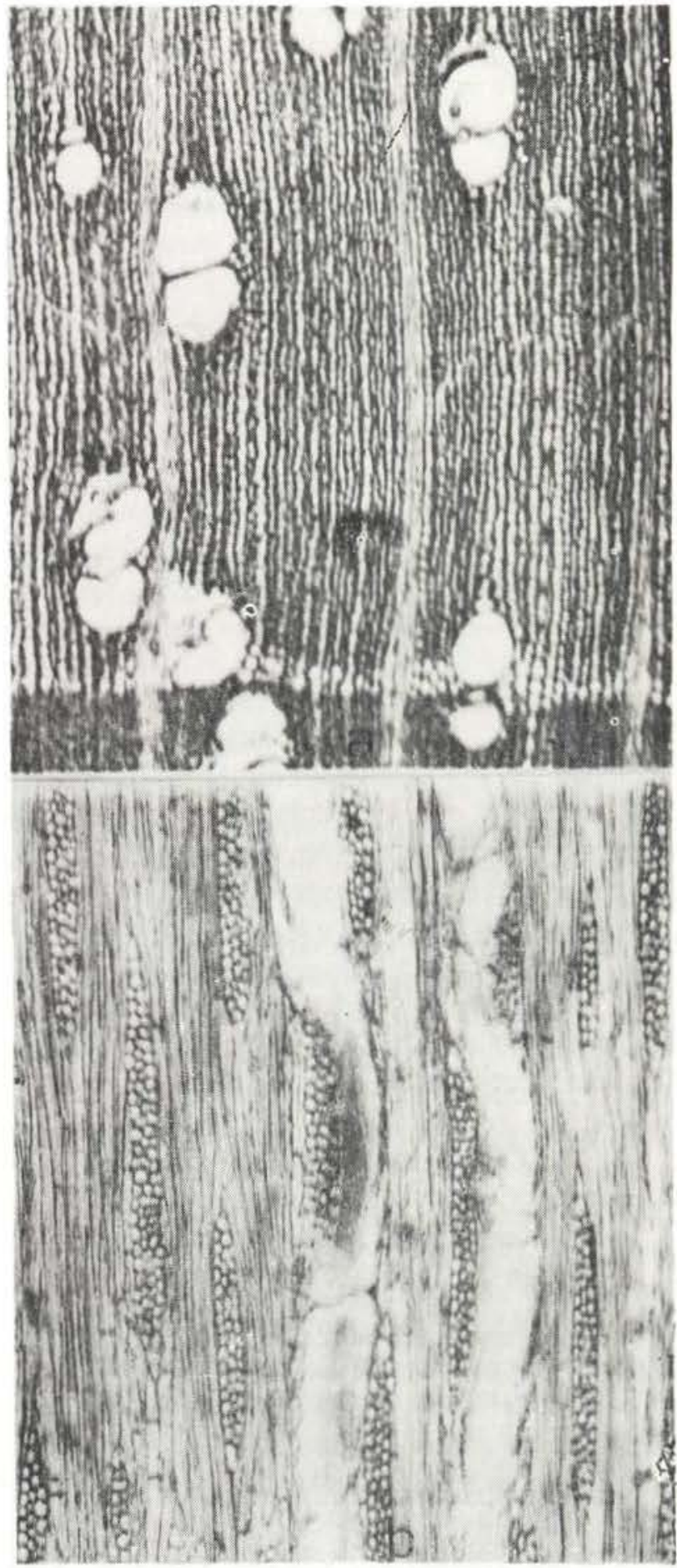

Foto II - Zanthoxylum dellomei: a) - secção transversal (50X); b) - secçâo tangencial (50X).

interrompidas, seriado, de $2-4$ células por série, mais comumente de 4 células. Fibras libriformes, parede menor que o lúmen, com $3 \mu \mathrm{m}$ de largura, diâmetro do lúmen varia de 6-9 $\mu \mathrm{m}$, em média $6 \mu \mathrm{m}$; curtas, variando de 1210-1510 

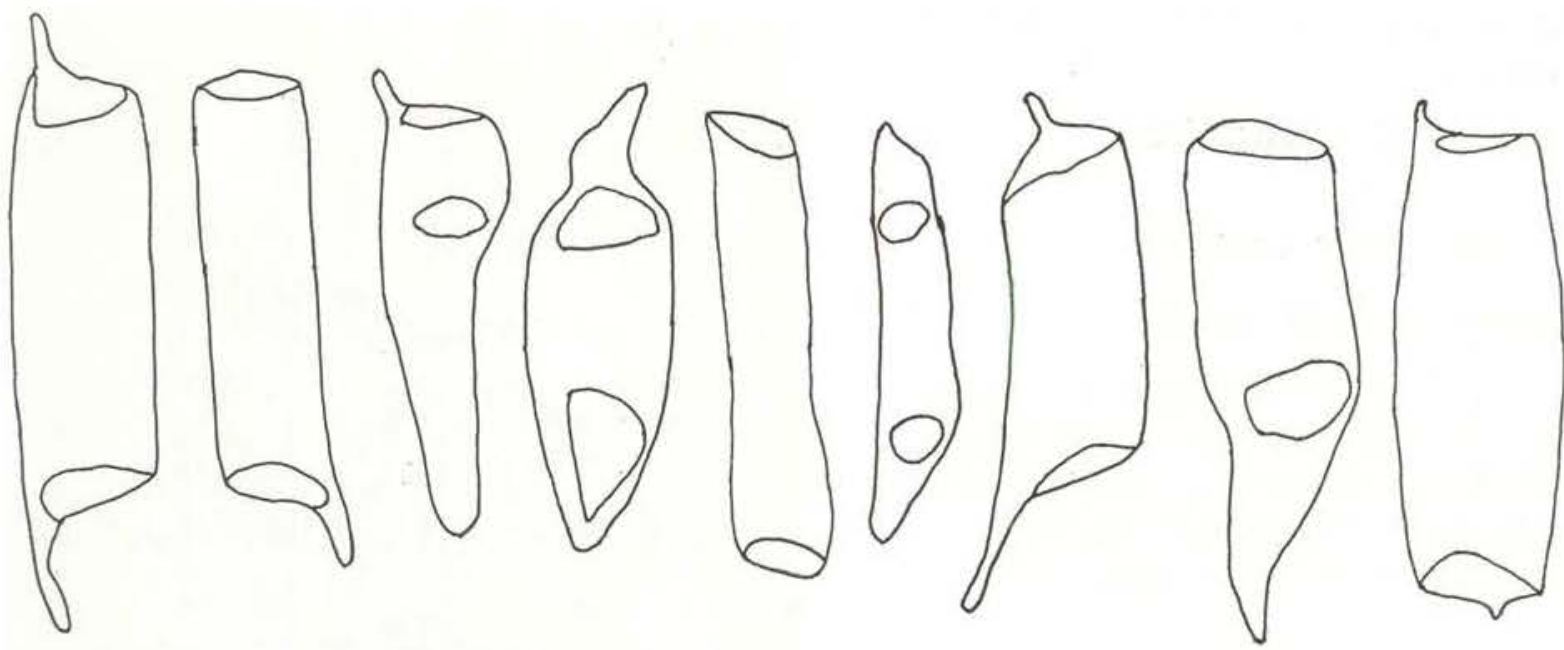

$0,2 \mathrm{~mm}$

Fig. 2 - Zanthoxylum dellomei

$\mu \mathrm{m}$, sendo que a maioria $(44 \%)$ varia entre 1301-1400 $\mu \mathrm{m}$. Cristais não foram observados. Camadas de crescimento definidas, às vezes, confundem-se com as linhas do parênquima terminal ou aparentemente demarcadas pelas fibras de parede mais espessa.

Emprego: Móveis, marchetaria, taboas, ripas, vigas, lambris, etc.

Material examinado: $X-1529$ (Herb. 12891), D. Coelho et al. s.n.

3. Zanthoxylum machadoi (de Albuquerque) Albuquerque, Acta Amazonica, 6(3):55, foto 37. 1976 (Suplemento) .

Fagara machadoi Albuquerque, Acta Amazonica, 1 (1): 24. 1971; idem, Acta Amazonica, 2 (2): 49-54, fig. 1. 1972.

a) DADOS GERAIS SOBRE A PLANTA

Árvore grande, até $30 \mathrm{~m}$ de altura e $45 \mathrm{~cm}$ de diâmetro de fuste (D.A.P.), bastante esgalhada; ramos densamente aculeados. Folhas paripinadas, pilosas, de 3-10 pares de folíolos, até cerca de $74,5 \mathrm{~cm}$ de comprimento; folíolos alternos ou opostos, grandes, oblongo-elíticos, coriáceos, glabriúsculos na face superior, revestidos de pilosidade velutina e verde-amarelados na face inferior, de base desigual, aguda ou subcordada e o ápice acuminado, acúmen curto, $7-19,5 \mathrm{~cm}$ de comprimento e $3,5-8 \mathrm{~cm}$ de largura, margem levemente crenulada, glandulífera. Fiores masculinas e femininas desconhecidas. Fruto 1-3 cocas conchiformes, subglobosas, deiscentes em duas valvas, de superfície áspera e curtamente pilosa, dispostas em ramos frutíferos paniculados, curtos, terminais, com râmulos subquadrangulares, articulados, suberoso-rugosos, curtamente pilosos; semente 1, subglobosa, levemente carinada.

Dispersão geográfica: Brasil, Estado do Amazonas, Município de Itacoatiara, rodovia ManausItacoatiara, Km 155, entre os rios Preto da Eva e Urubu no varadouro para picada 19 , lado direito.

Habitat: Encontrada em mata primária alta de terra firme, argilosa e úmida.

Fenologia: Colhida com frutos apenas uma vez no mês de fevereiro.

Nomes Vulgares: Desconhecidos.

b) DADOS GERAIS SOBRE A MADEIRA

\section{Características gerais da madeira}

Madeira pesada $\left(0,80 \mathrm{~g} / \mathrm{cm}^{3}\right)$; cerne cremeescuro, alburno amarelo com tonalidade esverdeada; insípida e inodora; grã direita; textura média; boa de trabalhar com ferramentas. Dado ter uma superfície lisa e brilhante, apresenta acabamento atrativo com polimento. 


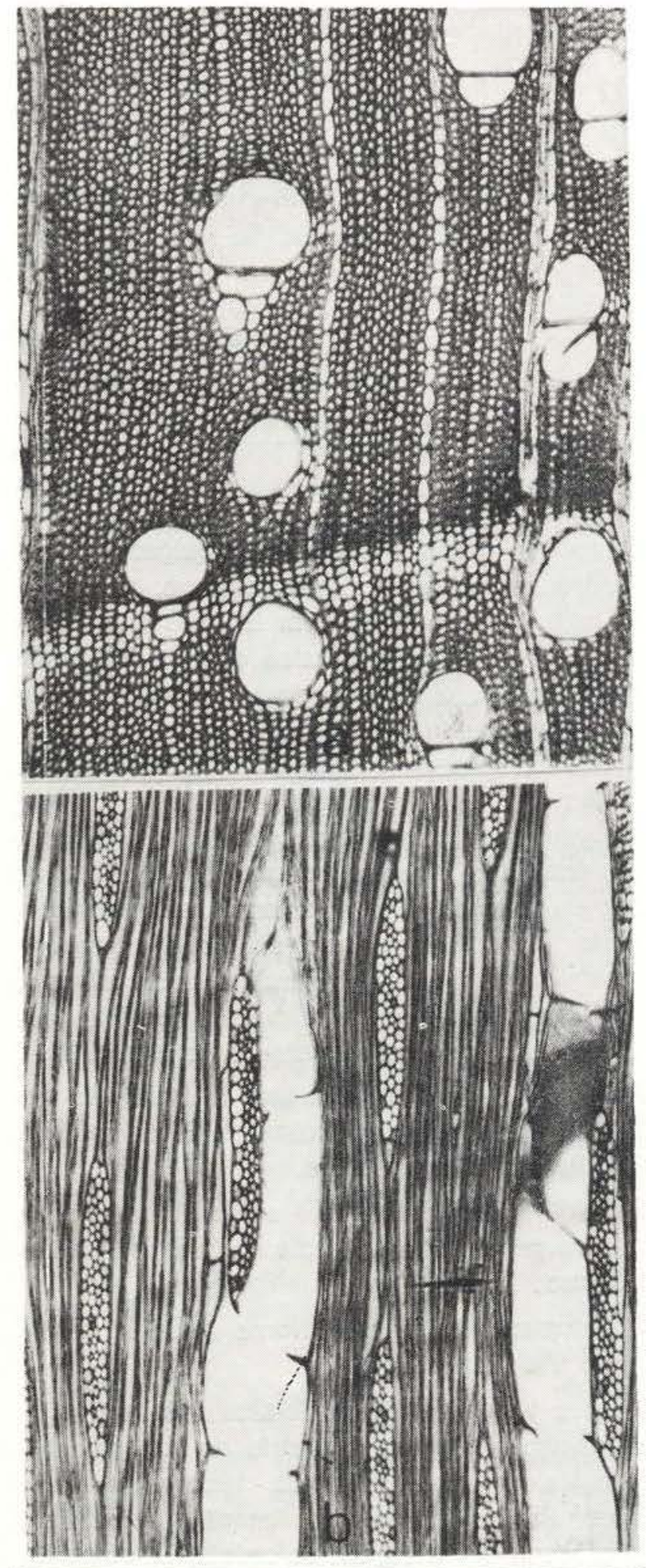

Foto III - Zanthoxylum machadoi: a) - secção transversal $(50 \mathrm{X})$; b) - secção tangencial (50X).

\section{Descrição microscópica}

Vasos de secção ovalada a circular, distribuição difusa havendo pequenos agrupamentos em cachos, de 3-6 pm de espessura, médios a grandes, de 140-220 $\mu \mathrm{m}$ de diâmetro tangencial, raros os de 70,100 e $110 \mu \mathrm{m}$, predominando os médios com 140-190 $\mu \mathrm{m}$ (84\%); vazios em sua maioria, alguns obstruídos por tilos; de pouco numerosos a numerosos, 6-12 por $\mathrm{mm}^{2}$. maioria de $8-10$, predominando os solitários $(50 \%)$, múltiplos de $2(30 \%)$, múltiplos de $3(16 \%)$, múltiplos de $4-5(4 \%)$; placas de perfuração simples, algumas inclinadas outras retas; pontuações intervasculares em disposição alterna; variando de 4 a $6 \mu \mathrm{m}$; circulares, poligonais a irregulares; abertura das pontuações circular e lenticular; elementos vasculares de muito curtos a muito longos, variando de 260-760 $\mu \mathrm{m}$ de comprimento, maior freqüência de $361-560 \mu \mathrm{m}$ ( $48 \%$ ), curtos a longos; encontram-se apêndices de um só lado, de ambos os lados e também de lados opostos, conforme desenho esquemático da Fig. 3 Raios heterocelulares, dispostos irregularmente; extremamente baixos a muito baixos, maior freqüência entre $401-900 \mu \mathrm{m}(92 \%)$, raríssimos os de $1080 \mu \mathrm{m}$; de 4-37 células de altura, predominando de $21-30$ células $(60 \%)$; de $2-4$ raios por $\mathrm{mm}$, maioria de $4(40 \%)$; pentasseriados com maior predominância $(62 \%)$, tetrasseriados $(28 \%)$, tri, bi e unisseriados $(10 \%)$, encontram-se, comumente, vários raios com céluals supostamente protetoras; pontuações radiovasculares do mesmo tipo das intervasculares, sendo porém menores. Parênquima axial paratraqueal marginal, disposto em faixas contínuas. onduladas, de 2 a 6 células em faixas descontínuas, delimitadas pelas camadas de crescimento; ainda parênquima paratraqueal abaxial, parênquima difuso; seriado, de 2-4 células por série, com maior freqüência de 4 células. Cristais não foram observados. Fibras libriformes, de parede menor que o lúmen, com $3 \mu \mathrm{m}$ de espessura, lúmen oscilando entre 6-12 $\mu \mathrm{m}$ de largura; curtas a longas, de 1200-1600 $\mu \mathrm{m}$, predominando as curtas, de 1200-1300 $\mu \mathrm{m}$ $(32 \%)$; encontra-se ainda uma variação de $1501-1600 \mu \mathrm{m}(28 \%)$. Camada de crescimento sempre presentes, demarcada pelas linhas do parênquima marginal.

Emprego: Cabos de ferramentas, escova de cabelo, tábuas, janelas, portas, ripas, vigas, etc. . 

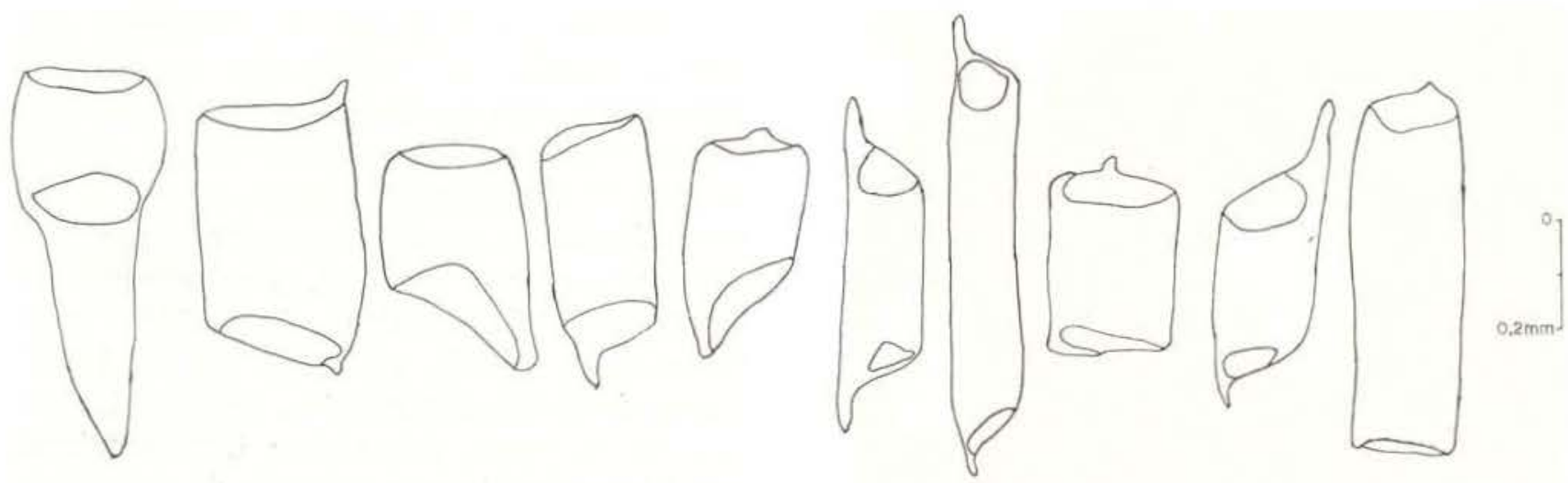

Fig. 3 - Zanthoxylum machadoi

Material examinado: $X-4177$ (Herb. 28470), W. Rodrigues et al. 9000 .

4. Zanthoxylum rhoifolium Lamarck, Encyc. Méthod. Botanique 2 (1):39.1786; DC. Prodromus... 1: 727. 1824; Engler in Martius, FI. Bras. 12 (2):174. 1874.

Fagara rhoifolium (Lamarck) Engler, in Engler \& Prantl, Nat. Pflanzenf. 3 (4): 118. 1896 e 2.' ed. 19.: 220. 1931; Lemée, FI. Gui. Franç. 2: 180. 1952; Cowan, Sellowia 12: 82. 1960; Albuquerque, An. Acad. Brasil. Ci. 40 (4): 502 . est. 1, fig. 1. 1968 e Bol. INPA, Pesq. Flor. 13: 7-8, fig. 6, $C$ e D. 1970.

\section{a) DADOS GERAIS SOBRE A PLANTA}

Arbusto a árvore, até cerca de $15 \mathrm{~m}$ de altura e $25 \mathrm{~cm}$ de diâmetro de fuste (D.A.P.); caule muito aculeado. Folhas imparipinadas ou repentinamente pinadas, densamente aglomeradas para o ápice dos ramos, de 3-17 pares de folíolos, alternos ou opostos, pequenos, oblongos, oblongo-elíticos ou elíticos lanceolados, membranáceos, esparsamente cobertos de pêlos estrelados em ambas as faces ou mais densamente pilosos na face inferior, de base levemente desigual, aguda a ligeiramente obtusa, subséssil, ápice obtuso ou agudo ou agudoacuminado, até cerca de $6,5 \mathrm{~cm}$ de cơmprimento e $2,5 \mathrm{~cm}$ de largura, margem mais ou menos profundamente crenada ou crenado-serrada, glandulífera. Inflorescência em panículas terminais ou axilares ou extra-axilares, compostas, curtas a amplas, cobertas de pêlos estrelados de muitas flores. Flores esbranquiçadas a esverdeadas, tetrâmeras a pentâmeras, curtamente pediceladas; cálice com lacínios triangularagudos; corola com pétalas esbranquiçadas a esverdeadas, oblongo-elíticas, agudas em ambas as extremidades; flores masculinas: estames 4-5, anteras suborbiculares, descoradas, ovário rudimentar; flores femininas: ovário 1-3-locular, lóculos subglobosos, dispostos sobre um disco espesso, estígma subséssil, obliquo ou coroado-peltado, estames rudimentares. Fruto 1-3 cocas pequenas, subglobosas, inicialmente esverdeadas, passando a avermelhadas até atingir a cor castanha quando maduras, cobertas de glândulas oleíferas esparsas.

Dispersão geográfica: Em todo o Brasil, Guiana Francesa, Venezuela, Colômbia, Equador, Bolivia, Paraguai e Argentina.

Habitat: Matas primária e secundária (capoeira) de terra firme, de solo argiloso ou argilosilicoso.

Fenologia: Colhida com flores e frutos de janeiro a dezembro.

Nomes Vulgares: Carne-de-anta (Manaus); Limãozinho (Manaus; Território do Amapá); Tamanqueira, Tamanqueira - da - terra - firme (Manaus; Pará; Território do Amapá); Coentrilho, Mamica-de-cachorra, M.-de-cadela, M.-de-porca, Tamanqueira-de-espinho, Tembetarana, Tembetaru-de-espinho (Pará); Betarú-amarelo, Laranjinho (Ceará); Espinho-de-vintém, Juvevê, Maminha-de-porca, Tamanqueiro, Tambetaru, Tembetaru, Tinguaciba (Rio de Janeiro); Guaritá, Mamica-de-porca, Tinguaciba, Tinguciba (São Paulo); Mamica-de-cadela (Rio Grande do Sul) . 


\section{b) DADOS GERAIS SOBRE A MADEIRA}

\section{Características gerais da madeira}

Madeira muito leve $\left(0,40\right.$ a $\left.0,50 \mathrm{~g} / \mathrm{cm}^{3}\right)$; cerne creme escuro, alburno creme brilhante; grã regular; textura média; gosto e cheiro não prounciado; boa de ser trabalhada com ferramentas manuais.

\section{Descrição microscópica}

Vasos de secção ovalada a circular, na maioria vazios, distribuição difusa, parede de 3-6 $\mu \mathrm{m}$ de espessura, pequenos a médios, de 60-120 $\mu \mathrm{m}$ de diàmetro tangencial, maior predominância de $80-110 \mu \mathrm{m}$ ( $68 \%$ ); muito numerosos a numerosíssimos, de 24-56 por $\mathrm{mm}^{2}$, predominância de solitários $(82 \%)$, múltiplos de $2(14 \%)$, múltiplos de $3(4 \%)$, notam-se alguns em forma de cacho; placa de perfuração simples, algumas retas, outras inclinadas; pontuações intervasculares de disposição alterna; de $3 \mu \mathrm{m}$ de diâmetro; circulares; lenticulares; elementos vasculares de curtos a muito longos, de $360-780 \mu \mathrm{m}$ de comprimento, maior ocorrência de curtos a longos com 360-560 $\mu \mathrm{m}$ $(64 \%)$, alguns com apêndices longos e outros curtos, em lados opostos e de um só lado, conforme mostra o desenho esquemático da Fig. 4. Raios heterogêneos, irregularmente dispostos, trisseriados predominantes $(56 \%)$, tetrasseriados $(34 \%)$, bi e unisseriados $(10 \%)$; de extremamente baixos a muito baixos, de 120-580 $\mu \mathrm{m}$ de altura, predominando os extremamente baixos, de $301-400 \mu \mathrm{m}(52 \%)$, ocasionalmente de 100 e $620 \mu \mathrm{m}$; de $6-28$ células de altura, raros de 2,3 e 4 células de altura, maioria de 11-20 células $(68 \%)$; de $3-7$ raios por $\mathrm{mm}$, maioria de $5-6$ raios $(52 \%)$; observa-se a presença de substância gelatinosa, não identificada, no parênquima radial; pontuaçōes radiovasculares do mesmo tipo das intervasculares. Parênquima axial apotraqueal, escasso, difuso e paratraqueal marginal, às vezes interrompido, em finissimas linhas acompanhando as camadas de crescimento e associadas aos poros que dão uma semelhança de anéis porosos; seriado, muito escasso. Fibras libriformes, lúmen variando de 6-9 $\mu \mathrm{m}$ de largura; parede de $3 \mu \mathrm{m}$ de espessura; de muito curtas a curtas, de 860-1170 $\mu \mathrm{m}$ de comprimento, maior freqüência de $961-1170 \mu \mathrm{m}(80 \%)$. Cristais pequenos, raros nas fibras e na parede de vasos quando observado no corte tangencial. Camadas de crescimento demarcadas por poros de menor diâmetro tangencial, associados também pelas

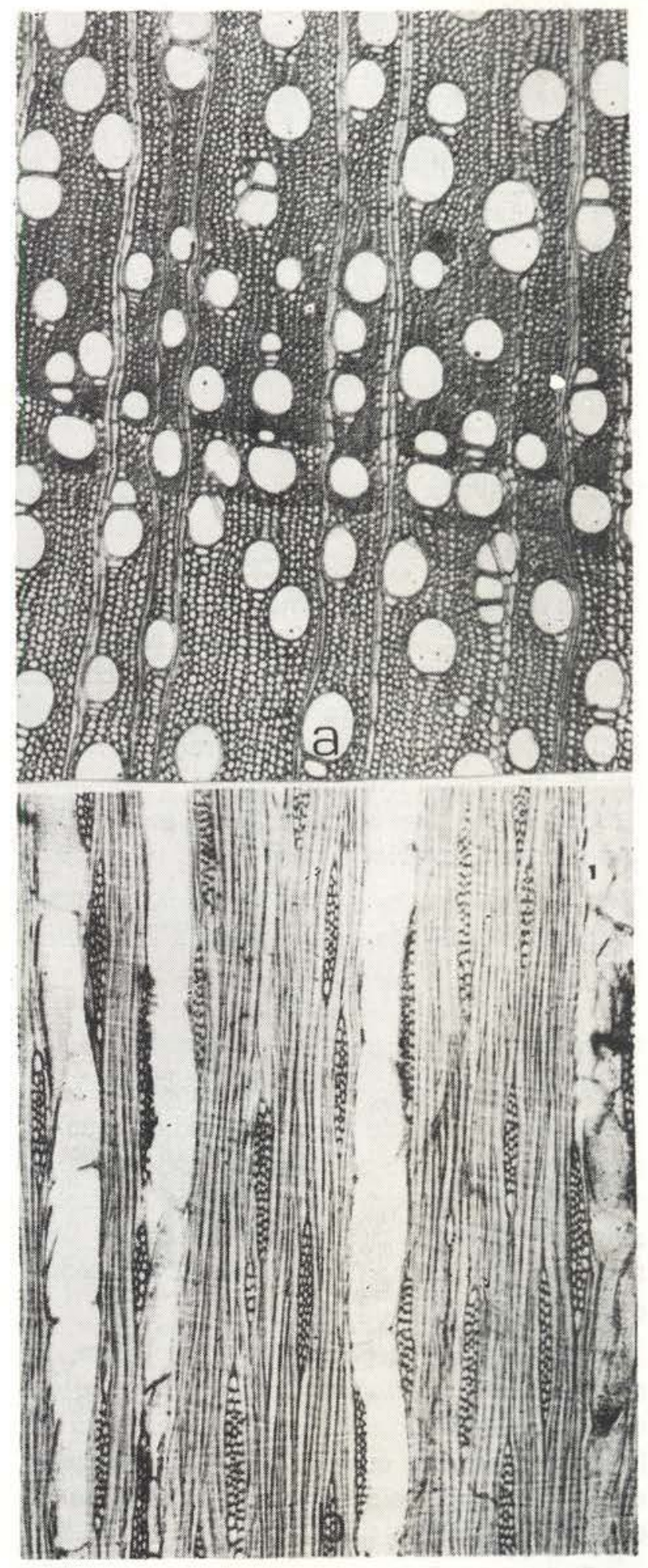

Foto IV - Zanthoxylum rhoifolium: a) - secção transversal $(50 \mathrm{X})$; b) - seç̧ão tangencial (50X). 


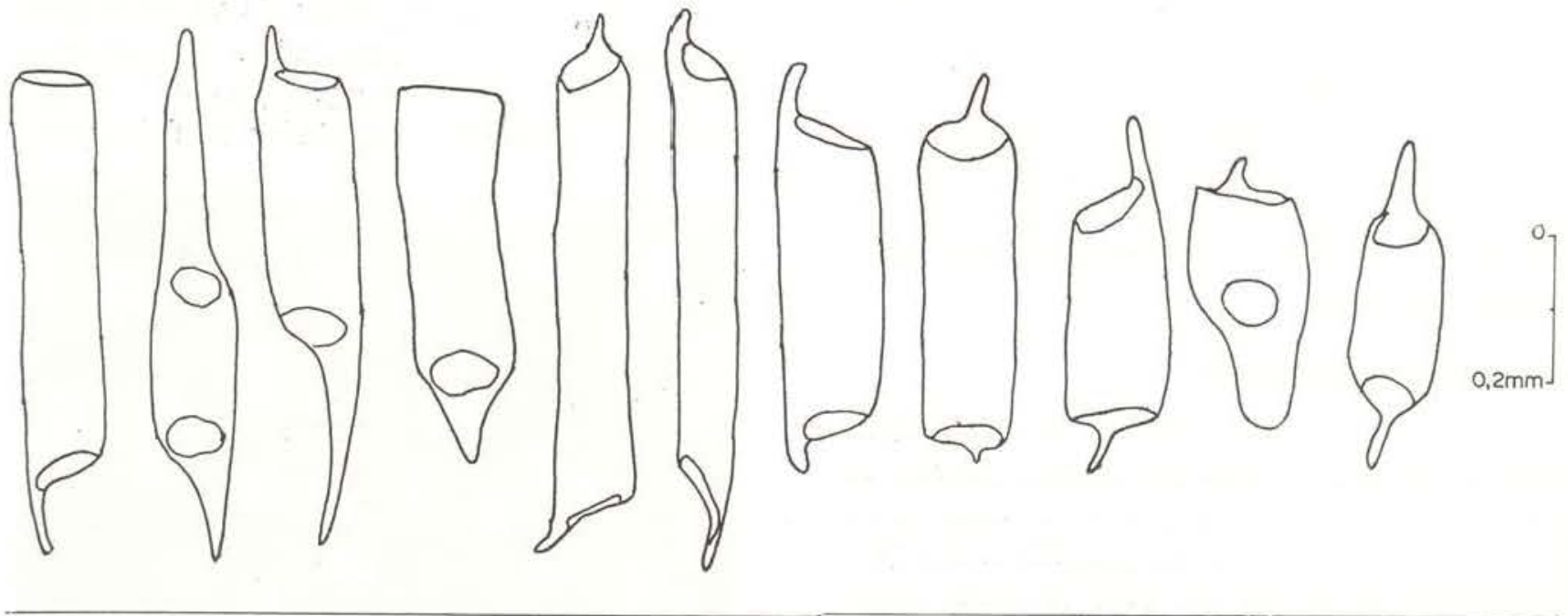

Fig. 4-Zanthoxylum rhoifolium

linhas marginais do parênquima e pela espessura da parede das fibras.

Empregos: Esta espécie (Corrêa, 1931, apud Cowan \& Smith, 1973) fornece madeira de boa qualidade, leve, dura, que se torna amarela ao ser cortada, porém empalidecendo em contato com $\cap$ ar. Própria para tamancos, construção civil, carpintaria, marcenaria, carroçaria, remos, cabos de instrumentos agrícolas e de ferramentas, cepas para escovas, ripas, assim como serve para tinturaria.

Material examinado: $X-4581$ (Herb. 65980), P. Lisboa, B. W. de Albuquerque \& D. Coelho, 965.

\section{DISCUSSÃo}

A fim de oferecer maior compreensão sobre os resultados de nossos estudos, resolvemos discutí-los sob a forma de itens agrupando-os de acordo com os caracteres comuns e diferenciais encontrados nas espécies: Zanthoxyifum compactum, $Z$. dellomei, $Z$. machadoi e Z. rhoifolium.

Poros - As espécies $Z$. compactum, $Z$. machádoi e Z. rhoifolium formam um só grupo, dado apresentarem, na sua maioria, poros solitários, enquanto que $Z$. dellomei, apresenta maior predominância de poros múltiplos de dois (geminados).

Outra característica importante para diferenciação entre as espécies, é que $Z$. machadoi, apresenta pequenas cadeias ou agrupamen- tos radiais de até cinco poros, enquanto que em Z. rhoifolium se encontram múltiplos de até três poros confinados radialmente. Todavia. em $Z$. compactum e $Z$. dellomei, raramente observarn-se pequenos agrupamentos radiais com até quatro poros. Em Z. rhoifolium, há uma característica distintiva peculiar e marcante em relação às demais especies; nela observase a presença de anéis porosos concêntricos e pontuações inter e radiovasculares de forma circuiar. Na espécie $Z$. compactum, as pontuações apresentam-se de forma poligonal para irregular. Nas espécies Z. dellomei e Z. machadoi a forma pode ser circular, poligonal e irregular. Quanto ao diâmetro tangencial dos poros, as espécies podem ser separadas individualmente do seguinte modo: poros extremamente pequenos a pequenos $(30-100 \mu \mathrm{m}) \mathrm{em}$ $Z$. compactum; poros pequenos a médios (151. $200 \mu \mathrm{m}$ ) em $Z$. dellomei e Z. rhoifolium e poros de médios a grandes $(100-300 \mu \mathrm{m})$, em $Z$. machadol.

Uma outra característica bem marcante e seletiva é a freqüência de poros por milímetro quadrado: em $Z$. compactum e $Z$. rhoifolium, eles vão de muito numerosos a numerosíssimos (de 12-80 por $\mathrm{mm}^{2}$ ); em Z. machadoi, eles vão de pouco numerosos a numerosos (de 6-20 por $\mathrm{mm}^{2}$ ), e em $Z$. dellomei, a freqüência de poros é pouco numerosa (de 6-10 por $\mathrm{mm}^{2}$ ).

Raios - Pela largura dos raios em número de células, foi possível também separar as espécies entre si da seguinte maneira: $Z$. com- 
QUADRO 1 - Principais caracteres anatômicos diferenciais do lenho das espécies estudadas

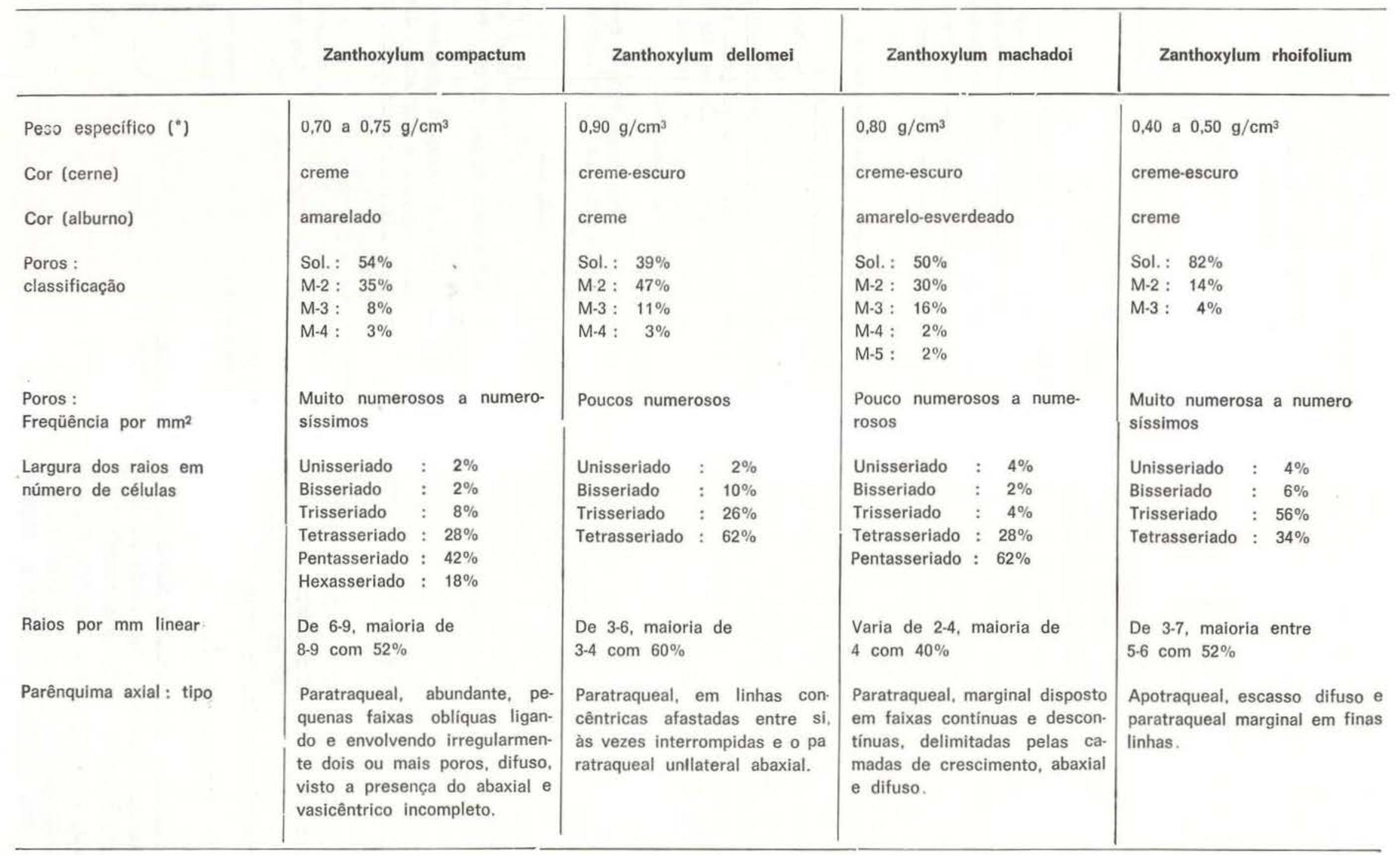


pactum e Z. machadoi, apresentam total predominância de raios pentasseriados, além da ocorrència particular de raios hexasseriados em $Z$. compactum, particularidade esta ausente nas demais espécies pesquisadas. Em Z . dello. mei, há predominância absoluta de raios tetrasseriados e em Z. rhoifolium, nota-se com maior frequência a presença de raios trisseriados.

Parênquima - Como caráter distintivo entre as espécies é possível separá-las quanto ao parênquima: abundante moderadamente escasso e escasso, observando-se que esta classificação só é válida para as espécies em estudo. A espécie $Z$. compactum apresenta parênquima abundante, paratraqueal, formando pequenas faixas oblíquas, ligando e envolvendo irregularmente dois ou mais vasos; as espécies Z. dellomei e Z. machadoi, têm parênquima moderadamente escasso, do tipo paratraqueal em linhas concêntricas e marginal afastadas entre si e, às vezes, interrompidas: em Z . rhoifolium o parênquima é escasso, apotraqueal e paratraqueal marginal, às vezes, interrompido em finíssimas linhas associadas aos anéis porosos $e$ às camadas de crescimento.

\section{CONCLUSÃO}

Há uma certa semelhança nos elementos, que englobam os tecidos celulósicos e lenhificados das espécies do gênero Zanthoxylum. Todavia, podemos caracterizá-los ou diferenciáos através de elementos específicos tais como: tipo e quantidade de parênquima, disposição, diâmetro e freqüência dos vasos por milímetro quadrado, forma das pontuações inter e radiovasculares, largura e altura dos raios em número de células.

Como auxílio à taxonomia, concluímos que as espécies aqui estudadas, anatomicamente, não säo tão difíceis de ser separadas através da anatomia microscópica do lenho.

\section{AGRADECIMENTOS}

Agradecemos a todos quanto direta ou indiretamente nos ajudaram, auxiliando na execução deste trabalho. Dada uma contribuição mais direta, somos gratos à Darlinda Bastos, peio trabalho datilográfico, Jorge Freitas pela confecção das lâminas histológicas, Moacir
Sena pelo preparo dos corpos de prova, aos coletores, Luiz Coelho e Dionísio Coelho e ao Técnico josé Wilson Meirelles, pelo seu atencioso trabalho de microfotografias dos cortes transversal e tangencial.

\section{SUMMARY}

This paper deals with a study on the dendrology and microscopic anatomical features of 4 species of the genus Zanthoxylum (Rutaceae): $\mathbf{Z}$. compactum, $\mathbf{Z}$. dellomei, Z. machadoi e Z. rhoifolium. For each species the following data are given :

1) Tree: its description, geographic distribution, habitat, phenology and vernacular names.

2) Wood: general characteristics, microscopic description, and common uses. Eight microphotograps of wood tissue, four schematic plates with several forms of vascular elements, and a table with the main features and the anatomical distinctions of the studied species are presented

\section{REFERENCIAS BIBLIOGRÁFICAS}

ALBUQUERQUE, B.W.P. de \& HONDA, M.

1972 - Rutaceae nova da Amazônia. Acta Amazo. nica. Manaus, 2 (2): 49-54.

ASSOCIAÇÃO BRASILEIRA DE NORMAS TÉCNICAS

1973 - Descrição dos caracteres gerais e anatômicos macro e microscópicos das madeiras de dicotiledoneas brasileiras. Rio de Janeiro, p. 18 (mimeografado)

CORREA, M. Pio

1931 - Dicionário das plantas úteis do Brasil e das exóticas cultivadas. Rio de Janeiro, Imprensa Nacional, vol. 1

COWAN, R.S. \& SMITH, L.B.

1973 - Flora ilustrada Catarinense. I parte: As plantas. Fascículo: Ruta. Itajaí, ed. por P. Paulino Reita, 89 pag., 25 figs., 13 map.

LE COINTE, Paul

1947 - Amazônia Brasileira III. Árvores e Plantas úteis (indigenas e aclimadas). São Paulo, Comp. Edit. Nacional, 2." ed. sér. 5.', Brasiliana, 251: 506p

LOUREIRO, A.A. \& LISBOA, P.L.B.

1979 - Madeiras do Município de Aripuanã e suas utilidades (Mato Grosso). Acta Amazonica, vol. 9 (1): Suplemento. $88 \mathrm{p}$.

MILANEZ, F.R.

1943 - Anatomia das principais madeiras brasíleiras das Rutaceae. Rodriguésia. Ano VIII, N. 16.22 pags., 18 estampas.

RECORD, S.J. \& HESS, R.W.

1940 - American woods of the family Rutaceae. Tropical Woods 64: 24-28.

1949 - Timbers of the New World. New Haven. Yale Univ. Press. 640p.

(Aceito para publicação em $07 / 04 / 81$ ) 